\title{
Interaction of Carbon Nanotubes Reinforced Hydroxyapatite Composite with Bacillus subtilis, P. aeruginosa and C. albicans
}

\author{
P. Khalid ${ }^{1,3}$, M. A. Hussain², P. D. Rekha ${ }^{1}$, C. Sanal ${ }^{4}$, S. Suraj ${ }^{4}$, M. Rajashekhar ${ }^{4}$, V. B. Suman 5 , \\ Sangappa ${ }^{6}$ and A. B. Arun ${ }^{1 *}$ \\ 'Yenepoya Research Centre, Yenepoya University, Mangalore, 575018, India; p.khalid@live.com, \\ rekhapd@hotmail.com, bhagwatharun@hotmail.com \\ 2Department of Electrical and Computer Engineering, King Abdulaziz University, Jeddah, 215895, KSA; \\ abujuveria@gmail.com \\ ${ }^{3}$ Department of Biotechnology, P. A. College of Engineering, VTU, Mangalore, 574153, India; \\ p.khalid@live.com \\ ${ }^{4}$ Department of Bioscience, Mangalore University, Mangalore 574199, India; \\ sanal2019@gmail.com, surajsuvarna19@gmail.com, profmrajashekhar@yahoo.co.in \\ ${ }^{5}$ Kasturba Medical College, Manipal University, Mangalore 575004, India; suman.vb14@gmail.com \\ ${ }^{6}$ Department of Studies in Physics, Mangalore University, Mangalore 574199, India; syhalabhavi@yahoo.co.in
}

\begin{abstract}
Hydroxyapatite (HA), as a bone mineral component, has been an attractive bioceramic for the reconstruction of hard tissues. However, its poor mechanical properties, including low fracture toughness and tensile strength, have been a significant challenge to the application of HA for the replacement of load-bearing and/or large bone defects.

Hydroxyapatite (HA) composite is reinforced with high purity and well-functionalized Multiwalled Carbon Naotubes (MWCNT>98 wt\%) having an average diameter of $15 \mathrm{~nm}$. The cellular response of f-MWCNT, MWCNT-HA composites were examined to model gram positive and gram negative Bacteria B. subtilis, P. aeruginosa and yeast C. albicans.

$\mathrm{Ca}\left(\mathrm{NO}_{3}\right)_{2} \cdot 4 \mathrm{H}_{2} \mathrm{O}$ and $\left(\mathrm{NH}_{4}\right)_{2} \mathrm{HPO}_{4}$ were used to synthesize $\mathrm{HA}$ in situ. MWCNT were functionalized by heating at $100^{\circ} \mathrm{C}$ in 3:1 ratio of $\mathrm{H}_{2} \mathrm{SO}_{4}$ and $\mathrm{HNO}_{3}$ for $60 \mathrm{~m}$ with stirring and dispersed in Sodium Dodecyl Benzene Sulphonate (SDBS) by sonication. Hydroxy Apatite (HA) particles were produced in MWCNTs solution by adding $\mathrm{Ca}\left(\mathrm{NO}_{3}\right)_{2} \cdot 4 \mathrm{H}_{2} \mathrm{O}$ and $\left(\mathrm{NH}_{4}\right)_{2} \mathrm{HPO}_{4}$ under vigorously stirring conditions. The composite were dried and washed in distilled water followed by heat treatment at $250^{\circ} \mathrm{C}$ to obtain CNT-HA powder. Using FTIR, FESEM and EDS does physicochemical characterization of the composite material.

The interaction of f-MWCNT and MWCNT-HA were tested on Bacillus subtilis, P. aeruginosa and C. albicans. The zone of inhibition and MIC studies were carried out with a concentration range from $62.5-1000 \mu \mathrm{g} / \mathrm{ml}$. The test result shows no zone of inhibition and MIC $>1000 \mu \mathrm{g} / \mathrm{ml}$ on bacteria and yeast. This result provides further evidence that the bio-nano interface can be developed for Carbon Nanotubes reinforced Hydroxyapatite composites for load-bearing bone implants, drug delivery and diagnostic applications.
\end{abstract}

Keywords: Hydroxyapatite, MIC, MWCNTs, Nanocomposites

*Author for correspondence 


\section{Introduction}

Nanotechnology is a rapidly emerging material science technology with global economic benefits. Concern over the lack of knowledge about the potential health risks associated with the handling of pure, unbound engineered nanomaterials has been expressed by investors, entrepreneurs, government agencies, and public health advocacy groups. Such concerns create potential barriers to the growth of Nanotechnology and the commercialization of nanoenabled products and devices could help address serious global problems concerning energy, transportation, pollution, health, medicine, and food. Therefore, early and accurate characterization of these materials is essential to determine their toxicological effects ${ }^{1}$. Certain characteristics have been identified which must be considered for the characterization of nanoparticles prior to study the toxicity. These properties are size, shape, dispersion, physical and chemical properties, surface area, and surface chemistry ${ }^{2-4}$. A synergy needs to be developed between the material science and the toxicological science to understand this complex issue of the nanoparticle toxicity ${ }^{5}$.

Preliminary in vitro studies showed evidence of cytotoxicity induced by carbon nanotubes ${ }^{6,7}$. According to some authors the toxicity of carbon nanotubes could be due to their surface chemistry ${ }^{8}$, degree of aggregation, physical contact ${ }^{10}$, diameter ${ }^{11-13}$.In contrast, other authors observed that chemical functionalization of different types of carbon nanotubes clearly reduced their cytotoxic effects $^{14-16}$.

Several toxicity mechanisms have been proposed for CNTs including interruption of trans membrane electron transfer, disruption/ penetration of the cell envelope, oxidation of cell components, and production of secondary products such as dissolved heavy metal ions or reactive oxygen species (ROS $)^{17-22}$. Toxicity of a CNT sample is dependent on its composition along with its geometry and surface functionalization. Several studies have suggested that well - functionalized, serum-stable CNTs are safe to animal cells, while raw CNTs or CNTs without functionalization show severe toxicity to animal or human cells at even moderate dosage $e^{23-28}$.

The aim of this study is to test the cellular response of f-MWCNT, MWCNT-HA composites to model grampositive and gram-negative bacteria $B$. subtilis, $P$. aeruginosa and yeast $C$. albicans. The MWCNT were functionalized by our previously developed protocol ${ }^{29}$ where heating with diluted acid does mild functionalization of the MWCNT so it can be well modified without damage.The SEM an FTIR revealed the nanotube structure were intact as well as the tubes were appended with functional groups like $(-\mathrm{COOH}$, $-\mathrm{OH},-\mathrm{C}=\mathrm{O}$ ) which makes them dispersible in water/culture media. These well-functionalized MWCNT is used to synthesize MWCNT-HAcomposite. The SEM of the composites revealed the sintering of HA over the MWCNT surface while FTIR confirms the attachment of $\mathrm{CO}_{3}$ and $\mathrm{PO}_{4}$ groups, which improve the biocompatibility of the nanocomposites with cells in culture.

The interaction result of $\mathrm{f}-\mathrm{MWCNT}$ and MWCNT-HA with $B$. subtilis, P. aeruginosa and $C$. albicans shows no zone of inhibition and MIC $>1000 \mu \mathrm{g} / \mathrm{ml}$. This result provides further evidence that the bio-nano interface can be developed for Carbon Nanotubes reinforced Hydroxyapatite composites for load-bearing bone implants, drug delivery and diagnostic applications.

\section{Experimental}

\subsection{Materials}

The MWCNTs samples were purchased from Nanoshel LLC, USA. The nanotube has a specified diameter 20-30 nm. Purity is greater than $98 \%$. Tween-20 was procured from Hi-media labs. Analytical grade of Calcium nitrate tetrahydrate $\mathrm{Ca}\left(\mathrm{NO}_{3}\right)_{2} \cdot 4 \mathrm{H}_{2} \mathrm{O}$ and di-ammonium hydrogen phosphate $\left(\mathrm{NH}_{4}\right)_{2} \mathrm{HPO}_{4}$ were purchased from Hi-media labs with a molecular weight of 164.15 and 132.06 respectively. Ammonia solution (25\%) was purchased from Merck. Nutrient Broth (NB), Nutrient Agar (NA), Peptone water, antibiotics Ciprofloxacin, Ketoconazole, Sabouraud Dextrose Broth (SDB) and Sabouraud Dextrose Agar (SDA) were procured from Hi-media laboratories, Mumbai, India. Methanol was procured from Central Drug House (CDH) Delhi, India. DMSO was procured from Merck Ltd., Mumbai, India.

\subsection{Functionalization of MWCNT}

According to our previously published $\operatorname{protocol}^{29}$, the Multiwalled Carbon Naotubes $100 \mathrm{mg} / 60 \mathrm{ml}$ were heated at $100^{\circ} \mathrm{C}$ in $3: 1$ ratio of $20 \% \mathrm{H}_{2} \mathrm{SO}_{4}$ and $20 \% \mathrm{HNO}_{3}$ for $60 \mathrm{~m}$ with stirring. These treated MWCNTs were washed until neutral $\mathrm{pH}$ and dried at $60^{\circ} \mathrm{C}$ for further use. 


\subsection{Bio-synthesis of HA}

The HA were synthesized in situ by sol-gel method ${ }^{29} .5 \mathrm{ml}$ of $0.5 \mathrm{M} \mathrm{Ca}\left(\mathrm{NO}_{3}\right)_{2} .4 \mathrm{H}_{2} \mathrm{O}$ is dissolved in distilled water and $\mathrm{pH}$ were adjusted to $\geq 10$ then $5 \mathrm{ml}$ of absolute ethanol is added to the solution. $10 \mathrm{ml}$ of $0.5 \mathrm{M}\left(\mathrm{NH}_{4}\right)_{2} \mathrm{HPO}_{4}$ is prepared in distilled water and $\mathrm{pH}$ was adjusted to $\geq 10$ and rapidly added to previously prepared $0.5 \mathrm{M}$ $\mathrm{Ca}\left(\mathrm{NO}_{3}\right)_{2} \cdot 4 \mathrm{H}_{2} \mathrm{O}$ under vigorously stirring conditions. $\mathrm{pH}$ of the mixed solutions were kept above or equal to 10 by adding ammonia solution. Stirring was continuing for $3 \mathrm{~h}$ followed by aging for $24 \mathrm{~h}$ at room temp. The gel was dried at $60^{\circ} \mathrm{C}$ overnight and repeatedly washed with distilled water followed by heating at $250^{\circ} \mathrm{C}$ in a muffled furnace for 30 minutes to obtain HA powder.

\subsection{Inclusion of MWCNT in HA Matrix}

Functionalized MWCNTs were dispersed in Sodium Dodecyl Benzene Sulphonate (SDBS) by sonication. Hydroxy Apatite (HA) particles were produced in above MWCNTs solution by adding $0.5 \mathrm{M} \mathrm{Ca}\left(\mathrm{NO}_{3}\right)_{2} \cdot 4 \mathrm{H}_{2} \mathrm{O}$ and $0.5 \mathrm{M}\left(\mathrm{NH}_{4}\right)_{2} \mathrm{HPO}_{4}$ under vigorously stirring conditions ${ }^{30} \cdot \mathrm{pH}$ of the solution were kept above or equal to 10 by adding ammonia solution. Stirring was continuing for $3 \mathrm{~h}$ followed by aging for $24 \mathrm{~h}$ at room temp. The composite were dried at $60^{\circ} \mathrm{C}$ followed by washing in distilled water for 3 to 4 times. Heat treatment at $250^{\circ} \mathrm{C}$ was done for $30 \mathrm{~min}$ to obtain CNT-HA powder.

\subsection{Cell Preparation}

Gram-negative bacteria $P$. aeruginosa (ATCC 9027), and gram-positive bacteria B. subtilis (ATCC 6051) and the yeast $C$. albicans were chosen as the model organisms for antibacterial and antifungal activity experiments. $P$. aeruginosa, and $B$. subtilis were grown in Nutrient Brothat $37^{\circ} \mathrm{C}$ and C. albicans were grown in Sabouraud Dextrose broth at $25^{\circ} \mathrm{C}$. Cells were harvested in the midexponential growth phase. The cultures harvested in the midexponential growth phase were centrifuged at $6000 \mathrm{rpm}$ for $10 \mathrm{~min}$ to pellet the cells, and the cell pellets were washed three times with saline solution to remove residual macro-molecules and other growth medium constituents. The pellets were then resuspended in a saline solution. Bacterial suspensions were diluted to obtain cell samples containing $10^{6}-10^{7}$ colony-forming units $(\mathrm{CFU} / \mathrm{mL})$ by setting the OD 650 at 0.3 for bacteria and 0.11 for yeast.

\subsection{Preparation of Resazurin Solution}

$270 \mathrm{mg}$ of Resazurin were dissolved in $40 \mathrm{~mL}$ of sterile distilled water using vortex mixer to get a homogenous solution.

\subsection{Zone of Inhibition and MIC Assay}

Bacterial and yeast cell interaction with MWCNTs and its composites were tested by zone of inhibition test using a simple well diffusion method. For MIC test, a sterile 96 well plate was labeled. A volume of $100 \mu \mathrm{L}$ of test material in DMSO was pipetted into the first row of the plate. To all other wells $50 \mu \mathrm{L}$ of sterile broth was added. Serial dilutions were performed using a multichannel pipette. Tips were discarded after use such that each well had $50 \mu \mathrm{L}$ of the test material in serially descending concentrations. To each well $10 \mu \mathrm{L}$ of Resazurin indicator solution was added. Using a pipette $30 \mu \mathrm{L}$ of sterile broth was added. Finally, $10 \mu \mathrm{L}$ of microbial suspension (0.3 OD adjusted suspension) was added to each well. Each plate was wrapped loosely with cling film to ensure that cultures did not become dehydrated. Each Plate has a set of positive, negative and a standard. The plates were prepared and placed in an incubator set at $37^{\circ} \mathrm{C}$ for $18-24 \mathrm{~h}$. The colour change was then assessed visually. Any colour changes from purple to pink or colourless were recorded as positive. The lowest concentration at which colour change occurred was taken as the MIC value.

\section{Results and Discussion}

\subsection{Measurement of Zone of Inhibition of Bacteria and Yeast}

The interaction of MWCNT and MWCNT-HA dispersed in $1 \%$ Tween-20 solution were evaluated first by zone of inhibition method. Figure 1 shows that MWCNT dispersed in tween-20 solutions exhibit no zone of inhibition activities; Sterile SDA and NA plates were prepared and $0.1 \mathrm{ml}$ of the inoculum from standardized culture of test organism was spread uniformly. Wells were prepared by using a sterile borer of diameter $10 \mathrm{~mm}$ and $100 \mu \mathrm{l}$ (To get the final concentration of 1000,500 and $250 \mu \mathrm{g} /$ well) of the test substance, standard antibiotic were added in each well separately. A standard antibiotic, Ketoconazole was tested against fungi and Ciprofloxacin against bacteria. The plates were placed at $4^{\circ} \mathrm{C}$ for $1 \mathrm{~h}$ to allow the diffusion 
of test solution into the medium and plates were incubated at a temperature optimal for the test organism for a period of time sufficient for the growth of at least 10 to 15 generations. The zone of inhibition of microbial growth around the well was measured in mm. MWCNT-HA composite and f-MWCNT did not show any inhibitory activity against B. subtilis, E. coli and C. albicans [Table 1].

To verify the reliability of the zone of inhibition method in this particular study, B. subtilis, $P$. aeruginosa and C. albicans were chosen as models to further examine their MIC after incubation with MWCNT and MWCNT-HA composite dispersions.

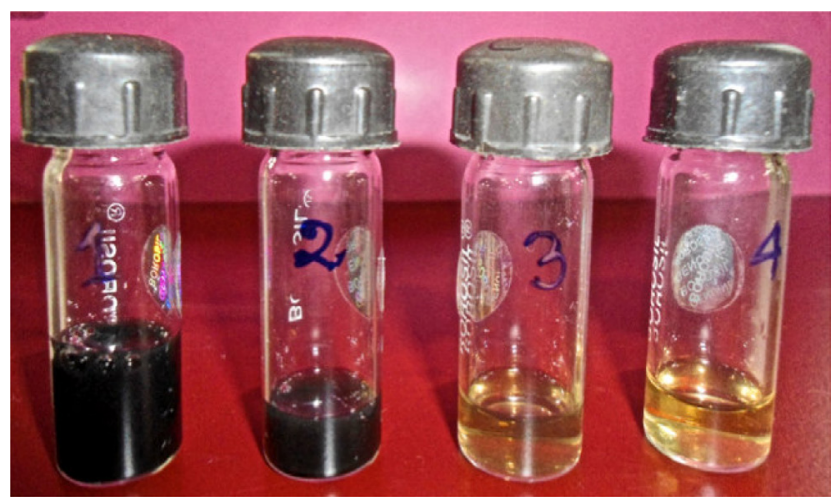

Figure 1. Photograph shows Stable Aqueous Dispersion of $\mathrm{f}$-MWCNT in Tween-20 at $1000 \mu \mathrm{g} / \mathrm{ml}, 500 \mu \mathrm{g} / \mathrm{ml}, 250 \mu \mathrm{g} /$ $\mathrm{ml}$ and $125 \mu \mathrm{g} / \mathrm{ml}$ (left to right).

Table 1. Zone of Inhibition of $\mathrm{f}-\mathrm{MWCNT}$ and MWCNT-HA composites against $P$. aeruginosa

\begin{tabular}{|c|c|c|c|c|c|c|}
\hline & \multicolumn{6}{|c|}{$\begin{array}{l}\text { Zone of Inhibition in } \mathrm{mm} \\
\text { Conc. } \mu \mathrm{g} / \mathrm{ml}\end{array}$} \\
\hline & \multicolumn{3}{|c|}{ P. aeruginosa } & \multicolumn{3}{|c|}{ B. subtilis } \\
\hline & 1000 & 500 & 250 & 1000 & 500 & 250 \\
\hline \multirow{5}{*}{$\begin{array}{l}\text { MWCNT-HA } \\
\text { composite } \\
\text { f-MWCNT } \\
\text { standard }\end{array}$} & 0 & 0 & 0 & 0 & 0 & 0 \\
\hline & 0 & 0 & 0 & 0 & 0 & 0 \\
\hline & 41.0 & & & 44.0 & & \\
\hline & \multicolumn{6}{|c|}{ C. albicans } \\
\hline & \multicolumn{2}{|c|}{$1000 \mu \mathrm{g} / \mathrm{ml}$} & \multicolumn{2}{|c|}{$500 \mu \mathrm{g} / \mathrm{ml}$} & \multicolumn{2}{|c|}{$250 \mu \mathrm{g} / \mathrm{ml}$} \\
\hline $\begin{array}{l}\text { MWCNT-HA } \\
\text { composite }\end{array}$ & \multicolumn{2}{|c|}{0} & \multicolumn{2}{|c|}{0} & \multicolumn{2}{|c|}{0} \\
\hline f-MWCNT & \multirow{2}{*}{\multicolumn{2}{|c|}{$\begin{array}{c}0 \\
61.0\end{array}$}} & \multirow{2}{*}{\multicolumn{2}{|c|}{0}} & \multirow{2}{*}{\multicolumn{2}{|c|}{0}} \\
\hline Standard & & & & & & \\
\hline
\end{tabular}

\subsection{Determination of Minimum Inhibitory Concentration (MIC) for Bacteria and Yeast}

The Minimum Inhibitory Concentration (MIC) of the test substances against $B$. subtilis, $P$. aeruginosa and C. albicans was determined by liquid broth method of two-fold serial dilution technique ${ }^{31,35}$. In this assay, the minimum concentration of each test substance required to inhibit the growth of microorganism was determined. For this assay, a series of assay tubes were prepared containing uniform volume $(1 \mathrm{ml})$ of sterile SD broth and equal volume of known concentration of test substance was added. The test substance in the first tube was serially diluted in two fold decreasing concentrations through the sixth tube and seventh tube was left without test substance as positive control. The tubes with the test substance i.e. from one to seventh were inoculated with $1 \mathrm{ml}$ of inoculum. The final concentration of test substance ranged from 1000 to $15.6 \mu \mathrm{g}$ per ml. Sterility controls was maintained in the experiment. The tubes were incubated at $28^{\circ} \mathrm{C}$ for $48 \mathrm{~h}$. Standard Ketoconazole (yeast) and Ciprofloxacin(bacteria) was tested as standard drug at concentrations ranging from 1000 to $15.6 \mu \mathrm{g}$ per $\mathrm{ml}$. The tubes were inspected visually to determine the growth of the organism as indicated by turbidity (In fact, turbidity of the culture medium is indicative of the presence of a large number of cells), the tubes in which the antibiotic is present in concentration sufficient to inhibit fungal growth remain clear. In experimental terms the MIC is the concentration of the drug present in the last clear tube, i.e. in the tube having the lowest concentration in which growth is not observed. MWCNT-HA composite and f-MWCNT did not show any inhibitory activity against $B$. subtilis, P. aeruginosa and C. albicans [Table 2].

MWCNT seem to be less toxic to bacteria as compared to SWCNT ${ }^{32-35}$. The reduced toxicity may be caused

Table 2. MIC Value of $\mathrm{f}-\mathrm{MWCNT}$ and MWCNTHA composites against $B$. subtilis, $P$. aeruginosa and C. albicans

\begin{tabular}{lccc}
\hline & \multicolumn{3}{c}{ MIC Value in $\mu \mathrm{g} / \mathrm{ml}$} \\
\cline { 2 - 4 } & B. subtilis & P. aeruginosa & C. albicans \\
\hline MWCNT- & $>1000 \mu \mathrm{g} / \mathrm{ml}$ & $>1000 \mu \mathrm{g} / \mathrm{ml}$ & $>1000 \mu \mathrm{g} / \mathrm{ml}$ \\
HAcomposite & \multicolumn{4}{c}{} \\
f-MWCNT & $>1000 \mu \mathrm{g} / \mathrm{ml}$ & $>1000 \mu \mathrm{g} / \mathrm{ml}$ & $>1000 \mu \mathrm{g} / \mathrm{ml}$ \\
Standard & 15.6 & 7.8 & $<15.6$ \\
\hline
\end{tabular}


by less tight interactions between bacteria and MWCNT, due to the higher inherent rigidity and possibly smaller van der Waal's forces at the MWCNT surface ${ }^{33}$. For the same reason, thin MWCNT with smaller diameter induce higher toxicity than the thicker ones ${ }^{35}$. When the effect of length of MWCNT was assessed, shorter MWCNT were more toxic to Pseudomonas fluorescens compared to long MWCNT $^{36}$. Toxicity of thin and short CNT was probably attributed to greater membrane interaction. When MWCNT are uncapped, debundled, short and dispersed in solution, the toxicity increased ${ }^{37}$. The purity of CNT has also been suggested to affect the toxicity. However, when comparing the toxicity between MWCNT in raw form (Fe as catalyst) and purified (heat-treated) in two bacterial strains, no difference in toxicity between the two forms of MWCNT was observed ${ }^{38}$, Heating purification possibly has limited the ability to modificate the surface compared to acid treatment, thus preserves toxicity of the raw form ${ }^{38}$. However, both studied CNT were suspended in the presence of Gum Arabic (GA, 0.25 wt\%), which may have modified their surface, affecting the toxicity. The MWCNT were toxic to a sensitive Escherichia coli strain while a pollutant resistant strain of Cupriavidus metallidurans was not affected ${ }^{38}$. One study evaluated the effects of MWCNT on fungal growth ${ }^{39}$. Entomopathogenic fungi Paecilomyces fumosoroseus conidia were incubated with $0.2 \mathrm{mg} / \mathrm{L}$ raw or carboxylated MWCNT for $1 \mathrm{~h}$ and up to $865 \mathrm{~h}$. After incubation sporulation and mycelium growth on solid medium were recorded. Sporulation increased after shorter exposures and reducted after longer exposures for both types of CNT. Exposure had no significant effect on fungal growth and biomass production, other than reduction of biomass after exposure to raw MWCNT for $865 \mathrm{~h}^{39}$. Mechanical effects of CNT, as observed for bacteria, likely induced effects.

In the present study, MIC assay is in good agreement with the results obtained by the zone of inhibition assay. A brief summary can be drawn from these antibacterial activity results: (1) individually dispersed MWCNT and its composites in Tween-20 solutions possess no antibacterial activities toward gram-positive bacteria, gram-negative bacteria and yeast.

\section{Conclusions}

The covalently functionalized Carbon Nanotubes become water dispersible but suffer the disadvantages of chemical modification of the original aromatic nanotube structure. Due to this reason mild oxidation of Carbon Nanotubes were done with $20 \%$ of $\mathrm{H}_{2} \mathrm{SO}_{4}$ and $\mathrm{HNO}_{3}{ }^{29}$. The SEM and FTIR revealed the nanotube structure were intact as well as the tubes were appended with functional groups $(-\mathrm{COOH})$ which makes them dispersible in water/culture media without/least damage.

The MWCNT-HA composites were prepared in MWCNTs solution by adding $0.5 \mathrm{M} \mathrm{Ca}\left(\mathrm{NO}_{3}\right)_{2} .4 \mathrm{H}_{2} \mathrm{O}$ and $0.5 \mathrm{M}\left(\mathrm{NH}_{4}\right)_{2} \mathrm{HPO}_{4}$ under vigorously stirring conditions. Synthesis of HA particles in the CNT solution which was prepared in advance, leads to an excellent dispersion of CNTs in HA matrix. The presence of CNT in composite of HA-CNT has caused the faster crystallization at lower temperatures compared to pure HA due to heterogeneous nucleation and creation of more diffusion pathways.

We conclude with the remark that properly functionalized CNTs are non-toxic to the bacterial and yeast cells. The MIC of the tested materials is $>1000 \mathrm{ug} / \mathrm{ml}$ while no zone of inhibition was observed when it is tested for antimicrobial activities. This result provides further evidence that the bio-nano interface can be developed for Carbon Nanotubes reinforced Hydroxyapatite composites for load-bearing bone implants, drug delivery and diagnostic applications

\section{References}

1. Powers KW, Brown SC et al. Research strategies for safety evaluation of nanomaterials. Part VI. Characterization of nanoscale particles for toxicological evaluation. Toxicol Sci. 2006; 90(2):296-303.

2. Murdock RC, Braydich-Stolle L et al. Characterization of nanomaterial dispersion in solution prior to in vitro exposure using dynamic light scattering technique. Toxicol Sci. 2008; 101(2):239-53.

3. Oberdörster G, Maynard A et al. Principles for characterizing the potential human health effects from exposure to nanomaterials: elements of a screening strategy. Particle Fibre toxicol. 2005; 2(1):8.

4. David B, Warheit. How meaningful are the results of nanotoxicity studies in the absence of adequate material characterization. Toxicol Sci. 2008; 101(2):183-5.

5. Robert $\mathrm{HH}$, Monthiouxet $\mathrm{M}$ et al. Toxicology of carbon nanomaterials: Status, trends, and perspectives on the special issue. Carbon. 2006; 44:1028-33.

6. Hussain SM, Braydich-Stolle LK et al. Toxicity evaluation for safe use of nanomaterials: recent achievements and technical challenges. Adv Mater. 2009; 21:1-11. 
7. Lam CW, James JT et al. A review of carbon nanotube toxicity and assessment of potential occupational and environmental health risks. Crit Rev Toxicol. 2006; 36:189-217.

8. Magrez A, Kasas S et al. Cellular toxicity of carbon-based nanomaterials. Nano Lett. 2006; 6:1121-25.

9. Wick P, Manser P et al. The degree and kind of agglomeration affect carbon nanotube cytotoxicity. Toxicol Lett. 2007; 168:121-31.

10. Liu S, Wei L et al. Sharper and faster "nano darts" kill more bacteria: a study of antibacterial activity of individually dispersed pristine single-walled carbon nanotube. Acs Nano. 2009; 3(12):3891-902.

11. Schiffman JD, Elimelech M. Antibacterial activity of electrospun polymer mats with incorporated narrow diameter single-walled carbon nanotubes. ACS Appl Mater Interfaces. 2011; 3(2):462-68.

12. Liu S, Zeng $\mathrm{TH}$ et al. Antibacterial activity of graphite, graphite oxide, graphene oxide, and reduced graphene oxide: membrane and oxidative stress. Acs Nano. 2011; 5(9): 6971-80.

13. Liu S, Ng AK et al. Antibacterial action of dispersed singlewalled carbon nanotubes on Escherichia coli and Bacillus subtilis investigated by atomic force microscopy. Nanoscale. 2010; 2(12):2744-50.

14. Sayes CM, Liang F et al. Functionalization density dependence of single-walled carbon nanotubes cytotoxicity in vitro. Toxicol Lett. 2006; 161:135-42.

15. Dumortier H, Lacotte S, Pastorin G, Marega R, Wu W, Bonifazi D, Briand J. P, Prato M, Muller S, Bianco A. Functionalized carbon nanotubes are noncytotoxic and preserve the functionality of primary immune cells. Nano Lett. 2006; 6:1522-28.

16. Riding MJ, Martin FL et al. Concentration-dependent effects of carbon nanoparticles in gram-negative bacteria determined by infrared spectroscopy with multivariate analysis. Environ Poll. 2012; 163:226-34.

17. Kang S, Pinault $M$ et al. Single-walled carbon nanotubes exhibit strong antimicrobial activity. Langmuir. 2007; 23:8670-73.

18. Klaine SJ, Alvarez PJJ et al. Nanomaterials in the environment: behavior, fate, bioavailability, and effects. Environ toxicol chem.. 2008; 27:1825-51.

19. Guo L, Morris DG et al. Bioavailability and redox activity in diverse carbon nanotube samples. Chem Mater. 2007; 19:3472-78.
20. Pulskamp K, Diabate $S$ et al. Carbon nanotubes show no sign of acute toxicity but induce intracellular reactive oxygen species in dependence on contaminants. Toxicol Lett. 2007; 168:58-74.

21. Li QL, Mahendra S et al. Antimicrobial nanomaterials for water disinfection and microbial control: potential applications and implications. Water Res. 2008; 42:4591-602.

22. Narayan RJ, Berry CJ et al. Structural and biological properties of carbon nanotube composite films. Mater Sci Eng B. 2005; B123:123-9.

23. Liu Z, Sun XM et al. Supramolecular chemistry on watersoluble carbon nanotubes for drug loading and delivery. ACS Nano. 2007; 1:50-6.

24. Chen X, Tam UC et al. Interfacing carbon nanotubes with living cells. J Am Chem Soc. 2006; 128:6292-93.

25. Cherukuri P, Bachilo SM et al. Fluorescence microscopy of single-walled carbon nanotubes in phagocytic cells. J Am Chem Soc. 2004; 126:15638-39.

26. Dumortier H, Lacotte $S$ et al. Functionalized carbon nanotubes are non-cytotoxic and preserve the functionality of primary immune cells. Nano Lett. 2006; 6:1522-28.

27. Kam NWS, O'Connell $\mathrm{M}$ et al. Carbon nanotubes as multifunctional biological transporters and near-infrared agents for selective cancer cell destruction. Proc Nat Acad Sci USA. 2005; 102:11600-5.

28. Liu Z, Tabakman S et al. Carbon nanotubes in biology and medicine: in vitro and in vivo detection, imaging, and drug delivery. Nano Res. 2009; 2:85-120.

29. Khalid P, Hussain MA. et al. Syntheis and characterization of carbon nanotubes reinforced hydroxyapatite composite. Indian J Sci Technol. 2013; 6(12):5546-1.

30. Najafi $H$, Nemati ZA et al. Inclusion of carbon nanotubes in a hydroxyapatite sol-gel matrix. Ceram Int. 2009; 35:2987-91

31. Eloff JN. A sensitive and quick microplate method to determine the minimal inhibitory concentration of plant extracts for bacteria. Planta Medica. 1998; 64:711-13.

32. Arias LR, Yang L. Inactivation of bacterial pathogens by carbon nanotubes in suspensions. Langmuir. 2009; 25:3003-12.

33. Kang S, Mauter MS et al. Microbial cytotoxicity of carbonbased nanomaterials: implications for river water and wastewater effluent. Environ Sci Technol. 2009; 43:2648-53.

34. Kang S, Herzberg $M$ et al. Antibacterial effects of carbon nanotubes: size does matter! Langmuir. 2008; 24:6409-13.

35. Zheng H, Liu L et al. Rapid determination of nanotoxicity using luminous bacteria. Anal Sci. 2010; 26:125-8. 
36. Riding MJ, Martin FL et al. Concentration-dependent effects of carbon nanoparticles in gram-negative bacteria determined by infrared spectroscopy with multivariate analysis. Environ Pollu. 2012; 163:226-34.

37. Kang S, Mauter MS et al. Physicochemical determinants of multiwalled carbon nanotube bacterial cytotoxicity. Environ Sci Technol. 2008; 42:7528-34.

38. Simon-Deckers A, Loo $\mathrm{S}$ et al. Size, composition and shape-dependent toxicological impact of metal oxide nanoparticles and carbon nanotubes toward bacteria. Environ Sci Technol. 2009; 43(21):8423-29.

39. Gorczyca A, Kasprowicz MJ et al. Physiological effect of multi-walled carbon nanotubes (MWCNTs) on conidia of the entomopathogenic fungus, Paecilomyces fumosoroseus (Deuteromycotina: Hyphomycetes). J Environ Sci Health A Tox. Hazard Subst Environ Eng. 2009; 44(14):1592-97. 